\title{
AS CONCEPÇÕES DE “NOVA UNIVERSIDADE” E “MULTIVERSIDADE” DE JOSÉ MARIANO DA ROCHA FILHO: MODERNIZAÇÃO CONSERVADORA
}

\author{
THE CONCEPTS OF “NEW UNIVERSITY” AND “MULTIVERSITY” OF JOSÉ MARIANO DA \\ ROCHA FILHO: CONSERVATIVE MODERNIZATION \\ LAS CONCEPCIONES DE “NUEVA UNIVERSIDAD” Y “MULTIVERSIDAD” DE JOSÉ \\ MARIANO DA ROCHA FILHO: MODERNIZACIÓN CONSERVADORA
}

Breno Antonio Sponchiado ${ }^{1}$

\begin{abstract}
RESUMO
O texto analisa as ideias mestras do pensamento de José Mariano da Rocha Filho, o pioneiro da interiorização do Ensino Superior no Brasil na UFSM. Perscruta o seu deslumbramento pelo modelo norte-americano de Universidade e seu projeto de transplantá-lo para o centro do Rio Grande do Sul, encontrando apoio do Governo Militar na sua proposta desenvolvimentista e dependente. Mostra que a "Nova Universidade" e a "Multiversidade" concebidas pelo Reitor representaram, por um lado, um avanço modernizador na estruturação, gestão e expansão do Ensino Superior e, ao mesmo tempo, um processo ideologicamente conservador e até reacionário, porquanto assentado em um ideário antidemocrático, centralizador e com um viés isolacionista. $\mathrm{O}$ que explica sua pouca duração. A pesquisa se instrumentalizou em análise crítica da produção bibliográfica de Mariano da Rocha e outros comentaristas e biógrafos.
\end{abstract}

PALAVRAS CHAVE: Reitor Mariano da Rocha Filho. Nova universidade. Multiversidade.

\begin{abstract}
This paper analyzes the main ideas of the thought of José Mariano da Rocha Filho, the pioneer of the interiorization of Higher Education in Brazil in the UFSM. Scrutinizes his fascination by the North American model of University and his project to transplant it to the center of Rio Grande do Sul, finding support from the Military Government in its developmental and dependent proposal. Shows that the "New University" and the "Multiversity" designed by the Dean represented on one hand, a modernizing advance in the structuring, management and expansion of Higher Education and, at the same time, an ideologically conservative and even reactionary process, because it is settled in antidemocratic, centralizing ideas and isolationist bias. What explains its short duration. The research was instrumentalized in critical analysis of literature production Mariano da Rocha and other commentators and biographers.
\end{abstract}

KEYWORDS: Dean Mariano da Rocha Filho. New university. Multiversity.

\section{RESUMEN}

El texto analiza las ideas maestras del pensamiento de José Mariano da Rocha Filho, el pionero de la interiorización de la Enseñanza Superior en Brasil en la UFSM. Examina su deslumbramiento por lo modelo norteamericano de Universidad y su proyecto de trasplantarlo para el centro de Rio Grande do Sul, encontrando apoyo del Gobierno Militar en su propuesta desarrolladora y dependiente. Muestra que la "Nueva Universidad" y la "Multiversidad" concebidas por el Rector representaran, de un lado, un avance modernizador en la estructuración, gestión y expansión de la Enseñanza Superior y, a la vez, un proceso ideológicamente conservador e incluso reaccionario, porque se asienta en un ideario antidemocrático, centralizador y de sesgo

\footnotetext{
${ }^{1}$ Professor da Universidade Regional Integrada do Alto Uruguai e das Missões - Câmpus de Frederico Westphalen. E-mail: sponchiado@uri.edu.br - ORCID: http://orcid.org/0000-0002-5000-8209

Submetido em: 24-09-2016 / Aceito em: 01-12-2016 / Publicado em: 27/01/2017.
}

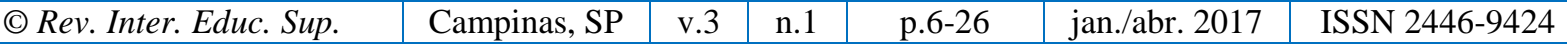


aislacionista. Ello explica su corta duración. La investigación se ha instrumentalizado en análisis crítico de la producción bibliográfica de Mariano da Rocha y otros comentaristas y biógrafos.

PALABRAS CLAVE: Rector Mariano da Rocha Filho. Nueva universidad. Multiversidad.

\section{INTRODUÇÃ̃o}

Tratando-se de desvendar aspectos do pensamento e da ação de Mariano da Rocha Filho, sobretudo a sua concepção de Universidade e sua articulação com a sociedade, lançaremos mão aos escritos do reitor. A obra básica analisada é Universidade para o desenvolvimento - áreas (distritos) geo-educacionais, de 1973, uma coletânea de textos que consolida as propostas enunciadas em outras bibliografias e reflete um balanço de suas atividades. Buscamos suporte também em documentação, biógrafos e na bibliografia sobre o tema em tela, aplicando-lhes uma hermenêutica em perspectiva histórica.

José Mariano da Rocha Filho é tido pela historiografia como o pioneiro da interiorização do Ensino Superior no Brasil ao liderar a criação da Universidade Federal de Santa Maria. Sua atuação na área educacional é amplamente divulgada e rememorada. Através de suas obras procuraremos analisar as razões deste ufanismo e a gênese e construção histórica de suas principais contribuições, enfeixadas nas expressões "Nova Universidade" e "Multiversidade".

O perfil biográfico de José Mariano da Rocha Filho (1915-1998) revela facetas que permitem melhor aquilatar sua atuação enquanto educador, administrador e atuante na educação pública. Sua filha Eugênia Maria da Rocha Barichello, declarou em entrevista à repórter Fernanda Arispe, do site "Notícias UFSM", em 2012, que seu pai tinha como inspiração em sua vida dois personagens marcantes:

\footnotetext{
Herdou do primeiro, seu pai, a praticidade e a facilidade de elaborar planos e projetos que previam todos os percalços possíveis. Do segundo, seu tio, herdou o lado humanitário, que buscava sempre um mundo melhor para viver. Contando sempre com a prática política que lhe proporcionou uma convivência saudável e amistosa com políticos seguidores das mais diversas ideologias (ARISPE, 2012, p. $1)$.
}

Um vínculo profundo com a Igreja Católica é outra marca do Reitor. "A família era presença garantida nas missas, especialmente nas dominicais” (ARISPE, 2012, p. 1). Descrito como um católico praticante, Mariano da Rocha era reconhecido pela sua enorme fé. Prof. ${ }^{a}$ Eugênia Maria conta que o pai era um “cristão diferente". Ele via também na religião uma oportunidade de esclarecimento e amadurecimento em busca da igualdade e da justiça entre os homens. Mas, narra a filha, "Não raro contestava o padre quando discordava com a interpretação da leitura do evangelho" (ARISPE, 2012, p. 1).

Para Eugênia Maria, "O pai acreditava na educação como um processo dinâmico e contínuo" (ARISPE, 2012, p. 1). Para que esse processo fosse bem sucedido, devia-se,

\begin{tabular}{l|l|l|l|l|l|l} 
(C) Rev. Inter. Educ. Sup. & Campinas, SP & v.3 & n.1 & p.6-26 & jan./abr. 2017 & ISSN 2446-9424
\end{tabular}


segundo o reitor, acreditar e motivar a equipe envolvida na execução de um projeto era fundamental. E narra fatos:

por vezes ele entrava nas salas de aula acompanhado de professores e profissionais renomados internacionalmente, tão logo avistava seus pupilos e seus colegas professores e já começava a chuva de elogios: "Esse é o melhor professor de química do mundo, não existe melhor, ele fez isso, ele fez aquilo, sabe fazer tal coisa...". Esse comportamento sempre fez com que os membros de sua equipe se engajassem de verdade em suas ideias mais utopistas (ARISPE, 2012, p. 1).

Entende a filha que "o jogo de cintura do pai também colaborou para que a maioria de seus projetos fossem concretizados" (ARISPE, 2012, p. 1). Nos anos 1960, enquanto ministrava aulas em uma universidade na capital da Alemanha Ocidental, Mariano descobriu que alguns países do Leste europeu tinham dívidas com o Brasil e não possuíam dinheiro para quitá-las. Em conversa com o deputado federal, e seu amigo, Tarso Dutra, Dr. Mariano conseguiu que a dívida fosse paga por meio do fornecimento de equipamentos que seriam suficientes para construir 11 planetários pelo país.

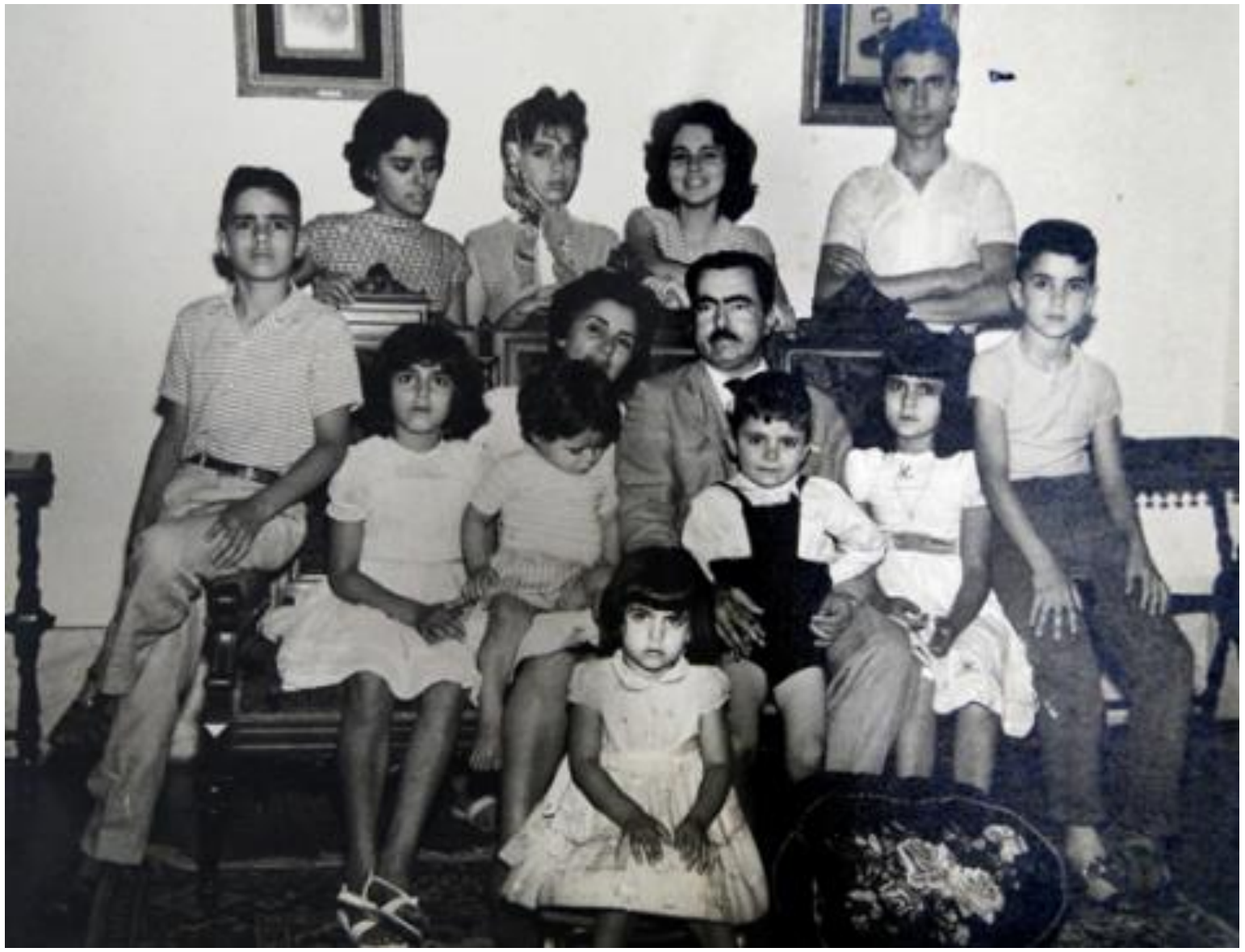

Figura 1. Mariano da Rocha Filho, sua esposa Maria Zulmira Velho Dias e onze de seus doze filhos.

Fonte: ARISPE, 2012. 
A UFSM - "Jogo de cintura" e de interesses

A UFSM, como outras IES gaúchas, nasce originária da UFRGS. Na sua conquista, pesou fortemente a situação de dificuldade, em que se encontravam as faculdades do interior do Estado. O mote foi reverter tal estado de coisas. Em 1945, Mariano da Rocha, foi eleito Diretor da Faculdade de Farmácia de Santa Maria e articula a Campanha de Incorporação das faculdades existentes no interior à Universidade de Porto Alegre, o que contava com amplo apoio da imprensa da época, especialmente dos jornais. Entraram em cena os deputados José Diogo Brochado da Rocha (PTB), Francisco Brochado da Rocha (PSD) e Tarso Dutra (PSD), que Constituintes em 1947, conseguiram incluir, na nova Constituição do Rio Grande do Sul, a anexação das faculdades de Direito e Odontologia de Pelotas e Farmácia de Santa Maria à Universidade de Porto Alegre.

No ano seguinte, reeleito Diretor da Faculdade de Farmácia, Mariano cria a ASPES (Associação Santa-mariense Pró Ensino Superior), sendo seu primeiro presidente. Por fim, em quatro de dezembro, é efetivada a incorporação das faculdades do interior. A partir desta data, a Universidade de Porto Alegre passou a denominar-se Universidade do Rio Grande do Sul. Tal medida não foi consensuada e até contou com franca oposição. Em janeiro de 1949, "inconformados com a vitória da Campanha de anexação das faculdades do interior liderada por Mariano da Rocha Filho, renunciam o reitor Armando Câmara e a cúpula diretiva da UFRGS” (REVISTA CONEXÃO UFSM, 2010, p. 13).

Em 1954, a Faculdade de Farmácia é federalizada junto com a UFRGS e anexada a ela a Faculdade de Medicina. Mariano Rocha, em 1955, em lista tríplice, é indicado seu Reitor. Em 14 de dezembro de 1960, por fim, contando com outros cursos - inclusive a Faculdade de Ciências Políticas e Econômicas, a Faculdade de Filosofia, Ciências e Letras e a Escola Superior de Enfermagem - é elevada à Universidade, por lei sancionada pelo presidente Juscelino Kubistchek de Oliveira (ROSSATO, 1997, p. 291).

\section{A Nova Universidade (NU)}

Quando eleito pela quarta vez Diretor da Faculdade de Farmácia de Santa Maria, em 1953, Mariano viaja para os Estados Unidos e Europa onde visita as principais instituições de ensino superior. Queria ver in loco, no primeiro Mundo, quais os modelos de ensino superior e reunir material para forjar a sua concepção de universidade. Ficou deslumbrado com a história norte-americana: "Foi somente após o Land Grant College Act', ocorrido durante o governo do Presidente Abrão Lincoln, que os Estados Unidos iniciaram a sua marcha à

\footnotetext{
${ }^{2}$ Também conhecida por Morrill Act, foi uma Lei do Congresso dos Estados Unidos (1862) que forneceu doações de terras aos estados para financiar a criação de escolas especializadas em agricultura e as artes mecânicas, dando origem às universidades.
}

\begin{tabular}{l|l|l|l|l|l|l} 
(C) Rev. Inter. Educ. Sup. & Campinas, SP & v.3 & n.1 & p.6-26 & jan./abr. 2017 & ISSN 2446-9424 \\
\hline
\end{tabular}


grande civilização americana”, afirmava (ROCHA FILHO, 1973, p. 84). O que saiu, foi uma cópia Tupiniquim?

O que ele vê lhe inspira a começar a escrever o livro "USM, a Nova Universidade", onde expôs as propostas básicas e a sua concepção de universidade. Mariano Rocha viu o êxito de sua campanha com a assinatura, pelo Presidente Castelo Branco, do Decreto-Lei n. 53, de 18 de novembro de 1966, que fixou as normas de organização para as universidades federais ${ }^{3}$.

"A universidade deve ser a alavanca do progresso de sua região educacional". Esta frase lapidar abre o Prefácio da obra Universidade para o desenvolvimento - Áreas (distritos) Geo-educaionais, publicado em 1973. Bem mostra o foco do autor de acelerar a marcha para o progresso. Na sua lógica, a educação é fator central. Acreditava que o ponto principal de estrangulamento para todos os setores era basicamente a educação. Mas qual educação, como operacioná-la? "A nova Universidade", para Rocha Filho, queria dizer "uma universidade criada em bases inteiramente novas" (ROCHA FILHO, 1973, p. 47).

\section{A Interiorização do Ensino Superior - um preconceito com o "Centro”?}

$\mathrm{Na}$ sua análise, Mariano ataca a vocação metropolista da universidade brasileira, que se circunscrevia a sua orla marítima e capitais. Aqui está talvez a originalidade do biografado:

Durante séculos o Ensino esteve limitado às capitais no litoral, e as populações do interior, que constituíam até bem pouco, nas estatísticas do último senso nacional de 1960, mais de $75 \%$ da população do país estavam praticamente à margem dos benefícios do ensino superior oficial (ROCHA FILHO, 1973, p. 51).

Lembra, na sequência, o fato histórico de a UFSM ter sido a primeira criada em uma cidade do interior, que não fosse capital de um Estado. "Este é o grande mérito, - continua esta foi a maior vitória na grande campanha por nós iniciada em Santa Maria, e que vale para nossa cidade a designação de 'Campeã da interiorização do Ensino Superior oficial no País'" (ROCHA FILHO 1973, p. 51).

No texto, o reitor critica a Lei Francisco Campos que, a seu ver, adotou o modelo da organização medieval para a Universidade brasileira, faltando-lhe tudo, inclusive a vivência universitária, pelo modelo de faculdades estanques e sem comunicação. $\mathrm{Na}$ sua visão, a universidade brasileira "era sumamente onerosa e existia unicamente no papel, pois era

\footnotetext{
${ }^{3}$ Disponível em: http://www.planalto.gov.br/ccivil_03/decreto-lei/1965-1988/Del0053.htm

${ }^{4}$ O PNU teve seus estatutos aprovados em junho de 1962 pelo Conselho Universitário e vigorou até 1969, quando a Reforma Universitária instituída pela lei $\mathrm{n}^{\circ}$ 5.540/68 exigiu a reestruturação da UFSM.
}

n.1 p.6-26
jan./abr. 2017 
formada de um grupo heterogêneo de Faculdades e não possuía racionalização" (ROCHA FILHO, 1973, p. 47).

Porém, destaca-se que Mariano da Rocha não pretende desfazer o mérito da Universidade medieval de origem cristã e a instituição que a manteve na Europa, o que destoaria de sua formação católica. Ao contrário, em trabalho anterior, afirmava que "foi à sombra da catedral de Notre Dame, em Paris, que surgiram os primeiros ensaios do ensino universitário, dado que faz da Universidade, ao contrário do que muitos creem, uma instituição inspirada nos princípios da civilização cristã” (ROCHA FILHO, 1973, p. 49).

Pelas viagens e contatos com comissões encarregadas de reformas universitárias na Inglaterra, na Alemanha e nos EUA, concluiu que a estrutura delas estava sucateada, defasada.

Deve ter uma estrutura tal, que lhe permita adaptar-se às necessidades de todos os tempos, que lhe permita evoluir sempre dentro de um mundo que muda constantemente e de forma tão rápida, na atualidade, que podemos afirmar, sem medo de erro, que jamais um cidadão esteve tão distante dos conhecimentos de seu tempo (ROCHA FILHO, 1973, p. 49).

O critério da universidade condizente com a sociedade hodierna devia ser "da preparação do maior número de candidatos, da melhor maneira possível, ao menor custo que se possa imaginar e no mais breve espaço de tempo" (ROCHA FILHO, 1973, p. 49). Como se vê, estava imbuído dos princípios da qualidade total e máxima eficiência.

Este pensamento de economicidade material leva ao autor propor uma nova configuração física da Universidade. Nesta nova modelagem a universidade deveria estar situada num campus, permitindo reunir os "elementos humanos e materiais, de forma a poder dispor dos mesmos com maior eficiência" (ROCHA FILHO, 1973, p. 53). Vejamos a sua noção de campus:

Um "campus" universitário deve estar constituído por uma parte de ensino que deve sempre caminhar juntamente com a pesquisa. Nessa parte de ensino, devemos destacar, em primeiro lugar, o centro que poderíamos chamar de estudos gerais, onde estariam os Departamentos, servindo disciplinas idênticas de várias carreiras, ou mesmo as disciplinas afins de uma mesma carreira (ROCHA FILHO, 1973, p. 53).

O que prega, pois, é o rompimento com o sistema de cátedras da velha universidade, onde havia uma multiplicação irracional e onerosa de laboratórios idênticos, e que ficaria oficializado na reforma universitária no Brasil de 1968. Aliás, como recorda, desde 1954, na USM vinha concentrando aparelhagens e pessoal em Departamentos e Institutos comuns. Via também a vantagem de os alunos ficarem mais próximos, pelo menos fisicamente. Defendia a centralização dos serviços administrativos, o que permitiria melhor aplicar os parcos recursos. 
O problema mais angustiante, porém, aos olhos do Reitor, era a grande demanda de alunos que batiam anualmente às portas das Universidades. "Temos como obrigação mestra, na NU, enfrentarmos o fato quantitativo na formação de técnicos para satisfazer as necessidades de nosso País" (ROCHA FILHO, 1973, p. 55). Lembrava que havia no Brasil 1.400 municípios sem médicos. Propunha novamente o caminho da economia, pela centralização e concentração de recursos humanos e materiais. Outra proposta era a flexibilização do currículo, que permitisse a transferência no primeiro ano de uma carreira (curso) para outra; havendo a necessidade do núcleo ou centro de estudos gerais e a adoção do sistema de créditos horários (ROCHA FILHO, 1973, p. 56).

Outra consideração foi o fator tempo, objetivando na prática a abreviar o período de formação. Eis sua solução: "Daí resulta que a Nova Universidade deve expurgar os programas de ensino atuais, retirando dali tudo aquilo que não seja essencial, sacrificando a erudição a favor da eficiência" (ROCHA FILHO, 1973, p. 57). Para evitar a sobreposição de disciplinas propõe revisão completa de currículos e estruturar a universidade em Centros ${ }^{5}$, como, aliás, já estava em andamento no campus da UFSM.

Em seus escritos, o Reitor é econômico em abordar outros pontos que não temas técnico-administrativos, como os referentes às questões pedagógicas. Ele mesmo admite essa faceta. Apenas sinaliza que se procura ministrar o ensino "cada vez mais prático, dentro do princípio que adotamos: 'o que ouço esqueço; o que vejo, lembro; o que faço, sei"' (ROCHA FILHO, 1973, p. 61). É a pedagogia empírica e pragmática de vertente norte-americana, apregoada no Brasil sobretudo pelos pioneiros da Escola Nova. Mas há uma crucial discordância com esta corrente de pensamento quanto à missão da Universidade. Enquanto o instrumentalismo recusa veementemente qualquer apelo a um projeto coletivo futuro de caráter transcendental a este mundo, o educador santa-mariense faz apologia da filosofia cristã. Diverge do vetor individualista da Escola Nova, para uma meta religiosa da educação. Ao tratar da missão da Universidade, enfatiza que nela "sejam os mestres capazes de descobrir e indicar às novas gerações novos caminhos, todos eles conduzindo à perfeição e, portanto, aproximando-as de Deus" (ROCHA FILHO, 1973, p. 53). Noutra passagem, enfatiza o compromisso social do educando, que além da satisfação dos reclamos individuais, não deve esquecer daqueles da comunidade em que vive. Mais adiante, replica sua concepção da NU como protagonista da melhoria das condições de vida, que estava a orientar cada vez mais o indivíduo para a comunidade. "Isso traz como consequência lógica a substituição do individualismo, pelo sentido do outro e pelo solidarismo cristão", arremata (ROCHA FILHO, 1973, p. 53).

\footnotetext{
${ }^{5}$ Esta ideia de Centros ou Setores Mariano da Rocha parece ter obtida de Rudolph Atcon, em sua obra "Ensino Superior no Brasil", que ele cita na p. 57 da obra de 1973.
} 
Ao final do capítulo "A Nova Universidade", o Reitor dedica uma página ao binômio Universidade e Cultura. Denuncia que as universidades no afã de formar profissionais competentes ou tecnólogos capazes, cientistas de valor ou pesquisadores "de raça" (sic, p. 62), abandonaram a sua meta precípua da formação do homem integral, do homem culto. Por esse termo, Mariano Rocha parece entender a capacidade de a pessoa humana situar-se dentro de sua área, capacidade de síntese. Defende que a Universidade retome sua tarefa central de ilustração, "de propiciar uma visão de panorâmica da plena cultura da época em que vivemos, de situar os homens em nosso tempo, de devolver-lhes a fé em seu próprio destino" (ROCHA FILHO, 1973, p. 62). Como se vê, há um retrocesso ideológico à mentalidade iluminista e humanista. "Necessitamos urgente formar e educar talentos especificamente sintetizadores, devemos humanizar o homem científico há muito contaminado pelo evangelho da rebelião, a grande falsidade de nossa época" (ROCHA FILHO, 1973, p. 62). Conclui-se, pois, que o modelo ideal de homem é o aquele que se conforma com seu tempo.

\section{A concepção de Área Geo-educacional}

Em seu elaborado ponto de vista, Mariano Rocha entendia que a Nova Universidade "não deve cingir-se unicamente dentro dos limites físicos de seus "campus". Ela deve ultrapassá-los, tendo em vista a necessidade de prestar serviço efetivos à zona geo-econômica onde está situada" (ROCHA FILHO, 1973, p. 58). Para explicar esse novo conceito, o Reitor recorre à expressão cunhada por Gilson Amado "A Universidade Cósmica", cuja origem ainda não identificamos. A educação devia extrapolar o círculo dos alunos e devia atingir também a todo o povo que vive na sua área geo-educacional:

\footnotetext{
Deve, ainda, procurar, através da pesquisa e da investigação dirigida, a solução dos problemas máximos da sua zona geo-cultural, aproveitando as riquezas naturais de sua zona geo-econômica. Deve, a "Nova Universidade", sob certa forma, presidir o progresso, orientando o desenvolvimento e melhoria das condições de vida, em sua zona geo-educacional (ROCHA FILHO, 1973, p. 53).
}

Entram, por força de seu pensamento, no vocabulário universitário novas expressões, como Área Geo-educacional, que vai ser novo cavalo-de-batalha do educador - que diz ter defendido e aplicado desde 1958.

Em seu escrito "A universidade deve ser o centro de desenvolvimento de sua zona geo-educacional", da mesma obra de 1973 que vimos analisando, Mariano Rocha reivindica, no planejamento da Nova Universidade, pelo menos dividir o pioneirismo em todo o mundo em fazer um levantamento dos problemas regionais, que resultou em sua publicação "Operação U.F.S.M.”, ou seja um "desenvolvimento planificado de Programas e Projetos geradores de riquezas econômicas e de bem estar social na área de ação da Universidade Federal de Santa Maria" (ROCHA FILHO, 1973, p. 86). O reitor recorda que em 1964 ouviu

\begin{tabular}{l|l|l|l|l|l|l} 
(C) Rev. Inter. Educ. Sup. & Campinas, SP & v.3 & n.1 & p.6-26 & jan./abr. 2017 & ISSN 2446-9424 \\
\hline
\end{tabular}


em um seminário na Universidade de Kansas, que as universidades deveriam ter um raio de ação aproximado de $100 \mathrm{~km}$. A seguir define o que seja uma zona geo-educacional:

Por zona geo-educacional de uma universidade nós entendemos uma área que, situando-se em torno de um centro universitário, envia a este Centro a sua juventude com a finalidade de ali estudar e preparar-se para enfrentar os problemas de desenvolvimento e se beneficia da ação dessa Universidade (ROCHA FILHO, 1973, p. 86).

Continua destacando que no seu modelo universitário, além da missão tradicional da Universidade de investigar e transmitir o saber, "acrescentamos uma terceira missão que é aquela de promover um perfeito entrosamento com as forças vivas de sua região, de sua zona geo-educacional, o estudo e a solução dos problemas que interessam e dizem respeito a esta zona geo-educacional" (ROCHA FILHO, 1973, p. 86)

Para implementar essa nova noção, Mariano entende que o primeiro passo é definir e delimitar a zona geo-educacional, para melhor equacionar seus problemas, solucionar suas necessidades no que diz respeito ao seu desenvolvimento. Vê-se que o entendimento é de uma universidade técnica, destinada ao desenvolvimento efetivo de uma região.

O diagnóstico prosseguiu com o estudo da área, que concluiu que as zonas centro e oeste do Estado do Rio Grande do Sul abarcavam sete micro-climas, - ou "zonas geográficas homogêneas"- "cada um com características próprias, e as vezes exclusivas, tendo como consequência diferentes tipos de culturas preferenciais, e apropriadas à criação de diferentes raças de animais". 6

Nota-se que a tônica da caracterização recai sobre aspectos morfológicos (geofísicos) e econômicos, ou seja, a aptidão natural da área para a agricultura e pecuária. As realidades da formação histórica e étnico-sociais das diferentes regiões são desconsideradas. Daí a medida seguinte de realizar estudos nas áreas (microclimas), "procurando fazer com que cada uma delas se desenvolva, em torno do mais importante dos seus núcleos humanos, uma área de experimentação da Universidade, em busca da verdadeira vocação da terra, de forma a poder indicar seu melhor uso nas lides agro-pastoris" (ROCHA FILHO, 1973, p. 59). O projeto previa a integração das Associações Rurais existentes, com a realização cursos para fazendeiros e lavradores.

\footnotetext{
${ }^{6}$ Por Zona micro-climática entendia zonas que possuíssem o mesmo clima, o mesmo solo e a mesma precipitação pluviométrica (p. 87). Foram estabelecidas 7: Zona da Fronteira/Campanha - produção de lã, gado de corte e suas indústrias; Planalto central: plantio de trigo; Missões - lavoura de soja, trigo, algodão e sua industrialização; Alto Uruguai - criação de suínos e gado leiteiro, produção de conservas e laticínios; Zona da Serra do Sudeste: frutas e beneficiamento de minérios; Depressão Central - arroz; Encosta Inferior do Nordeste - fumo.
} 


\title{
Alinhamento com o ideário do regime militar
}

Qual o posicionamento de Mariano Rocha frente ao Golpe de 1964 e sua postura durante o regime militar no Brasil? Lima e Konrad (2012), em seu estudo sobre o comportamento das forças políticas em Santa Maria, destacam uma marcha local de agradecimento ao Golpe, no qual havia participantes universitários. Um dos seus protagonistas foi o nosso biografado:

A cidade se preparava para organizar uma das Marchas da Família, com Deus, pela Liberdade, mas tendo o Golpe ocorrido antes, o ato se transformou em uma comemoração, uma manifestação de agradecimento às Forças Armadas. $\mathrm{O}$ tom dos discursos foi revelador quanto à expressão desse discurso legitimador a que vínhamos nos referindo. Sobressaem-se tanto a negatividade dos depostos quanto a positividade dos golpistas. Um dos principais organizadores da Marcha, o reitorfundador da UFSM, José Mariano da Rocha Filho (LIMA; KONRAD, 2012, p. 767).

O jornal local A Razão publicou o discurso do Reitor, cujo conteúdo nos permite perceber o seu posicionamento:

\begin{abstract}
A revolução democrática do Brasil, iniciada e executada com o brilho de uma parada militar, pelas gloriosas forças do Exército Brasileiro, deve continuar até que os culpados paguem seus hediondos crimes aqueles que nos queriam entregar com as mão amarradas aos pelotões de fuzilamento aqueles que desejavam substituir por imagens humanas a imagem de Deus nos corações de nossos jovens, aqueles que visavam substituir o nosso Cruzeiro do Sul pela Ursa Polar, aqueles que pensavam macular o nosso pavilhão auri-verde com a foice e o martelo, aqueles que desejavam acorrentar o Brasil ao mundo comunista, aqueles que um dia pensaram que seria possível amordaçar para sempre o nosso povo e dispor livremente das riquezas de nosso subsolo, e do amado solo Brasileiro ao serviço do comunismo ateu (A RAZÃO, 19/04/1964: 06, citado por LIMA - KONRAD, 2012, p. 768).
\end{abstract}

Nota-se o discurso em que o cavalo-de-batalha era o anticomunismo e a defesa da democracia. Acrescenta-se o ingrediente religioso, com o temor do ateísmo, que ameaçava as bases cristãs da nação brasileira.

Mariano da Rocha, na sequência, menciona o universo estudantil e faz um apelo:

Que nenhum traidor possa jamais voltar a perturbar a paz social que tanto necessita o Brasil para seu desenvolvimento, que a UNE, a UEE, a UGES e os nossos grêmios acadêmicos e estudantis sejam expurgados dos maus elementos que deles se apoderaram ou neles se infiltraram sob o bafejo e com a orientação dos traidores da Pátria / Lembrai-vos jovens estudantes que só há um caminho para o Progresso e este é o da Educação ruas de que essa de nada serve se não for banhada pelo sol da liberdade (Idem).

Os autores citados enfatizam que, segundo esta fala, legitimava-se assim a 'Operação Limpeza' entre os estudantes. Que tinha o objetivo de acabar com os focos de resistência e de

n.1 p.6-26
jan./abr. 2017 
pressão popular e para isso passou a cassar mandatos e direitos políticos, expurgar militares e funcionários públicos e prender lideranças ligadas ao trabalhismo ou às esquerdas.

Retenhamos, para a compreensão da atividade de Mariano Rocha, essa adesão ao novo governo no país, que vai lhe render maiores espaços de articulação administrativa e cargos de efetivo poder de decisão. Lembramos alguns, na área educacional: Membro do Conselho Federal de Educação. Criador das áreas ou distritos geo-educacionais, onde defendia que a vocação do solo e a cultura da região deveriam orientar a educação. Foi de sua autoria, datado de 1968, o projeto que disciplinava a implantação de campus universitário fora da cidade-sede da universidade: a multiversidade, como ele denominava. Ocupou o cargo de Conselheiro do Projeto Rondon e o idealizador e criador do primeiro campus avançado do ensino superior na Amazônia, em agosto de 1969, lembrando que antigo campus da UFSM em Boa Vista, no estado de Roraima, deu origem à Universidade Federal de Roraima.

Consta que já conhecido no meio educacional, "Marianinho foi convidado, no final dos anos 1960, pelo presidente do regime militar, Costa e Silva, a ser Ministro da Educação. Ele não aceitou. Em resposta afirmou que ainda tinha muito o que fazer em Santa Maria" (DIÁRIO DE SANTA MARIA, 2015). Em contrapartida às benesses recebidas, mantêm-se fiel nas fileiras governistas, concorrendo ao Senado em 1978 pela ARENA (Aliança Renovadora Nacional).

Na época, não somente a UFSM, como outras universidades do país sofriam com a carência de equipamentos. Como realizava conferências no Exterior e tinha forte ligação com a Universidade de Bonn, na Alemanha, descobriu que os países do leste europeu deviam muito dinheiro ao Brasil. Foi então que conseguiu com o ministro da Educação, Tarso Dutra, que os valores fossem pagos em equipamentos" (ROCHA FILHO, 1962, p. 39).

De outra parte, é recorrente na historiografia encontrarem-se expressões maximizando as ideias de Mariano da Rocha Filho como "fundamentais no processo de democratização do acesso ao ensino superior no Brasil e na América Latina, e acabaram orientando o desenvolvimento e os rumos do ensino superior." (UFSM, s.d.). Como se vê a noção de democracia para os nosso biografado e propagandistas de sua obra parece se restringir a oportunidade de acesso, em ampliar o número bancos nas instituições de ensino superior para mais alunos. O que não deixa de ser uma característica, um avanço em um país marcadamente elitista e excludente no que refere aos estudos universitários. Mas muito estreita, pois envolve somente a questão de acesso sem levar em conta a decisão, a organização e principalmente a gestão democrática. Coisas que o Mariano deve ter visto nos EUA e Europa. 


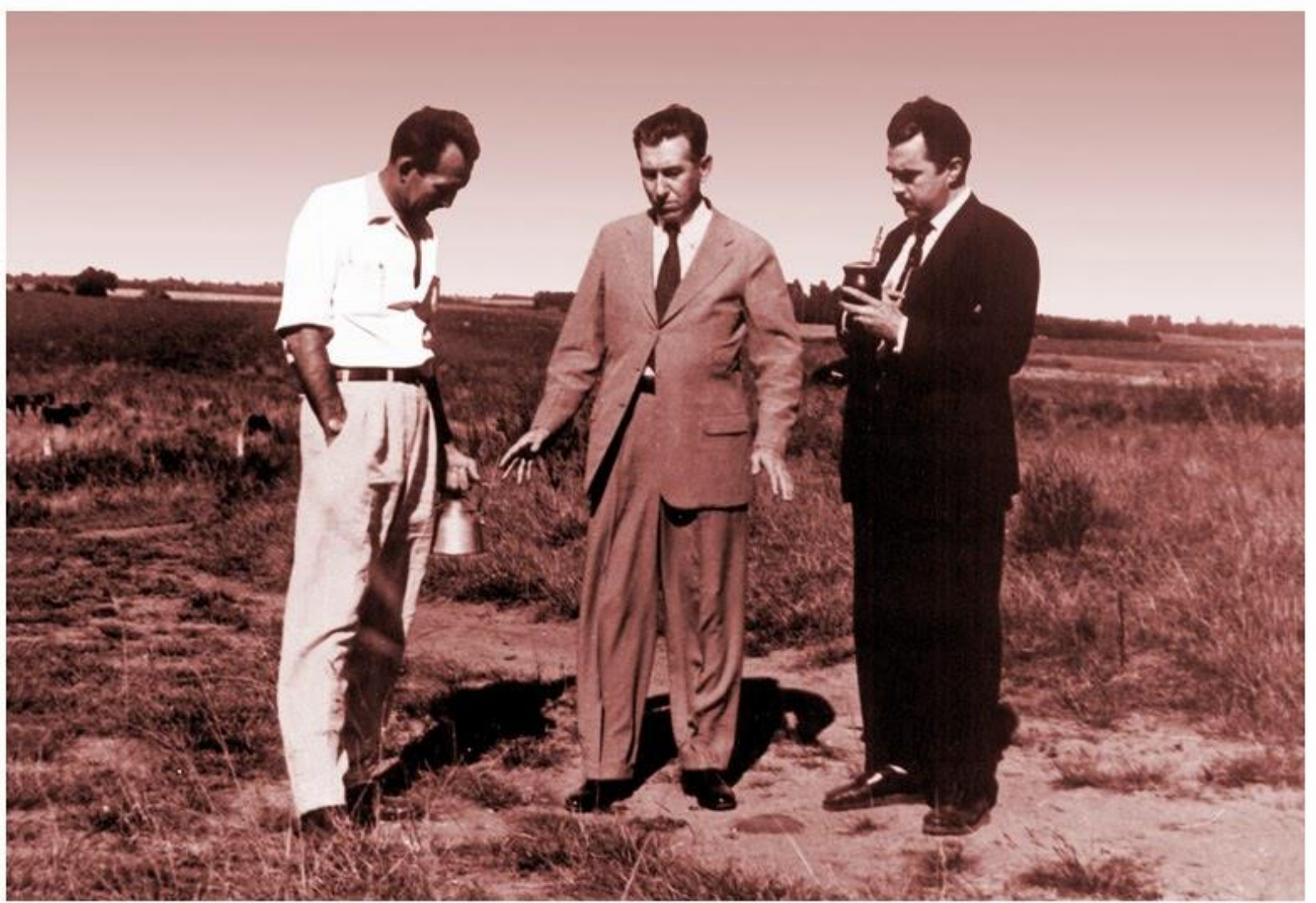

Figura 2. Evaldo Behr (E) mostra ao Dep. Tarso Dutra (C) e ao Prof. Mariano da Rocha Filho (D) a área a ser doada à ASPES, e abrigar o campus da UFSM, em $1959^{7}$. Fonte: Foto de Bortolo Achutti, "Brenner de Santa Maria".

\section{O projeto Multiversidade}

Cabia à universidade, dizia o Reitor, no afã de acelerar o desenvolvimento social e econômico da área Geo-educacional, incentivar a criação de órgãos regionais, associações de municípios e especialmente procurar criar fundações educacionais reunindo os esforços da população. A Nova Universidade devia ir ao encontro do desejo de comunidades em possuir estabelecimentos de Ensino Superior, através de extensões universitárias. Para tanto obteve do Conselho Federal de Educação do Brasil os Pareceres de n. 405 e 611, que permitiram a criação durante o ano de 1969 destas extensões. As condições para uma cidade requerer uma extensão da UFSM previam: - abranger uma região com quatro mil estudantes no $2^{\circ}$ ciclo (chamado S/High School); - que possa contribuir com prédio, material escolar, laboratório (com valor não inferior a um milhão de cruzeiros); - que a zona microclimática seja capaz de aportar duzentos mil cruzeiros anuais, no mínimo, para manutenção e funcionamento de duas

\footnotetext{
${ }^{7}$ Postado em 21 dezembro de 2014 - disponível em <http://brennerdesantamaria.blogspot.com.br/2014/12/umafoto-historica-autor-bortolo-achutti_21.html $>$ Acesso em: 15 abril 2016.
} 
séries inicias de um curso preferencialmente de uma área fundamental de ensino (ROCHA FILHO, 1973, p. 93-94).

Outra medida defendida pelo Reitor era a que aos alunos das extensões fossem assegurada, após o segundo ano, a possibilidade de completarem os seus estudos através de créditos correspondentes no Campus central da Universidade. Era mais uma prática que transplantava, copiada como ele mesmo admite dos junior'colleges norte-americanos ou das faculdades juniors de outros países (1973, p. 94). Propunha também que a Universidade pudesse disponibilizar os estudos complementares, correspondentes ao chamado $1^{\mathrm{o}}$ ciclo universitário no próprio local da extensão, possibilitando ali diplomar professores para a escola primária e média (ROCHA FILHO,1973, p. 94).

A política proposta de implantar extensões não significava criar novos centros autônomos de ensino superior. Antes sim, estender a ação da UFSM a novas regiões, mantendo a centralização do controle pedagógico e a criação de cursos e livrando-se do ônus da manutenção financeira. Esse ponto de vista Mariano da Rocha coloca no prefácio da sua obra de 1973, quando se debatia as reformas da Universidade - e que estavam em jogo seus postulados. O princípio do controle estatal é assim defendido:

\footnotetext{
É necessário que a responsabilidade de polo geo-educacional seja dada não a toda e qualquer universidade, mas especialmente às universidades pertencentes de certa forma ao Estado... Através dessas é que deverão as comunidades unir seus esforços no sentido de poderem encaminhar para uma solução desenvolvimentista os problemas que dizem respeito às diferentes áreas geo-educacionais (ROCHA FILHO, 1973, p. 11).
}

Noutra passagem reitera que assim precisva ser porque elas as Universidades estatais estariam estão diretamente vinculadas ao governo, enquanto que as universidades particulares ou as fundações de direito privado não poderião ser obrigadas a participar de uma rede, ficando na possibilidade de cooperarem. Vê-se que a instituição de ensino, neste pensamento, deve estar subserviente ao projeto do governo de plantão. Às universidades não estatais não restava outra saída a não ser subsidiar filiando-se a uma estatal. As universidades estatais poderiam delegar às universidades particulares mediante convênios assinados e revelando um acordo mútuo, "mas a responsabilidade de alavanca de progresso, a cooperação obrigatória deverá ser deferida somente às universidades estatais", complementa.

O projeto Multiversidade no entender de seu propugnador, significava uma universidade de campos múltiplos, mas a preposição multi se restringe unicamente à questão de suas localizações geográficas. Nada de diversidade, pluralismo como poderia sugerir, pois foram formatadas num mesmo padrão, dependentes do Campus Matriz, que detinha a palavra final nas questões essenciais de sua organização e, em última análise, do seu futuro. Para Mariano Rocha aquele modelo era o possível naquela circunstância. "A Multiversidade, a

n.1 1 p.6-26
jan./abr. 2017 ISSN 2446-9424 
universidade de campos múltiplos, nos parece ser a realidade imperativa nos dias que correm, da mesma forma a implantação das universidades comunitárias ligadas às universidades polo" (ROCHA FILHO, 1973, p. 12).

Mas sua proposta encerrava outro objetivo, mais ideológico e político. Falando das consequências da Multiversidade, apontava:

a) Facilitar o estudo dos menos favorecidos; e b) por motivos de formação manter a estes jovens durante mais 4 semestres, ou 2 anos junto a seus pais, longe dos centros que poderiam de qualquer forma alterar seu pensamento e torna-los vulneráveis às forças desagregadoras da subversão (Rocha Filho, 1971, p. 11, in NEVES, 1992, p. 103).

Este raciocínio está consonante com o pensamento das autoridades católicas e de parcela da elite intelectual, em que viam o mundo rural como sendo propício à formação dos jovens, pois distante dos grandes centros urbanos, antro de vícios e ideias libertinas, nocivas. Merece destaque o inimigo mor das instituições hegemônicas naquele momento, o comunismo. Parte da crença de isolar os indivíduos em tenra idade dos focos de corrupção e garante-se a sua formação do caráter em princípios morais desejáveis para a sociedade (no caso a Igreja e o Estado).

Essa mesma mentalidade vemos em representantes do clero. Por exemplo, em época anterior, em dois artigos "A Ação Católica nas zonas rurais", de 1942, o Pe. Pedro Luiz, PSM, examina a diferença entre o meio urbano e o meio colonial. Aponta as marcas da vida citadina: possui maior grau de instrução, sucedem-se as ideias, devido ao jornal, cinema, teatro, rádio; maneiras mais finas e desnaturais; materialização da vida; os perigos são maiores; miscelânea de ideias, de religiões, de matizes da vida. Já a colônia seria o inverso, a "mesma religião é praticada com mais zelo e mais consciência no conjunto" (LUIZ, 1941, p. 103). "Sua instrução começa na cartilha e acaba em geral na rabiça do arado". Depois: "A consciência é sua guia suprema. Em se tratando com desconhecidos surge a desconfiança, se for de negócios, essa chega ao auge". E mais adiante: "Para com o sacerdote, não. Esse constitui exceção belíssima: o colono segue de olhos fechados a palavra do padre. O eclesiástico é sempre seu conselheiro. Deposita nele confiança ilimitada" (LUIZ, 1941, p. 105). E arremata: "O contato com centros populosos é fatal". Os canais próprios para o vazamento dessa "contaminação" são: estrada de ferro, que introduz pessoas de todas as cores morais, diversidade de costumes, jornais e revistas profanantes; o rádio, as modas.

Deparamo-nos com um paradoxo: ao mesmo tempo em que se defende uma modernização, via tecnologia e racionalidade econômica, vemos uma desconfiança dos avanços da técnica, das vantagens dos meios de comunicação, pois é nas grandes cidades em que eles se mais se encontram. A questão não é a tecnologia, mas o seu uso que, segundo esse pensamento, deve ficar restrito à difusão do ideário e projeto do Governo.

n.1 1 p.6-26
jan./abr. 2017 
Admite que enfrentou resistências e custou-lhe muitas lutas. Em 29 de dezembro de 1969 os municípios que já haviam encaminhado suas solicitações, compareceram e firmaram a documentação para o funcionamento de extensões da UFSM. Para Rocha Filho, o fator que preponderou na decisão daquele órgão foi a prudência em localizar as extensões em municípios-polo. Igualmente teria pesado a tipificação dos Cursos, partindo da seguinte metodologia: "As entidades que se apresentarem como mantenedoras das Extensões sugeriram as instalações de determinados Cursos. A Universidade, por pesquisas realizadas través de seus especialistas, verificava a oportunidade ou não da instalação dos Cursos propostos" (ROCHA FILHO, 1973, p. 113).

Percebe-se que a proposta relativiza a autonomia das Fundações Mantenedoras em definir o curso que desejam, dando soberania à lógica dos "especialistas", voltada unicamente ao mercado. Alguns cursos foram desaprovados. "A Universidade sugeriu o Curso ideal para atender as necessidades mais imediatas da área, levando em conta principalmente a capacidade de absorção do profissional pelo mercado do trabalho local, pois sempre entendemos que é muito mais perigoso o excedente profissional do que o excedente aluno" (ROCHA FILHO, 1973, p. 113). E cita o caso de Três Passos, que desejava o Curso de Letras e os técnicos concluíram por Administração de Empresas, e cujos resultados teriam sido positivos. Frederico Westphalen, por alguns testemunhos, também pleiteou o curso de Filosofia, para atender uma demanda certa de seminaristas, mas recebeu o Curso de Letras.

As extensões criadas foram as seguintes: Santa Cruz do Sul (Direito e Ciências Contábeis); Bagé (Estudos Básicos Rurais); Santana do Livramento (Pedagogia); São Gabriel (Pedagogia); Alegrete (Letras e Pedagogia); São Borja (Pedagogia e Letras); Santiago (Pedagogia e Letras); Santo Ângelo (Letras e Pedagogia); Santa Rosa (Letras e Pedagogia); Três de Maio (Administração): Frederico Westphalen (Letras); Cruz Alta (Letras). 


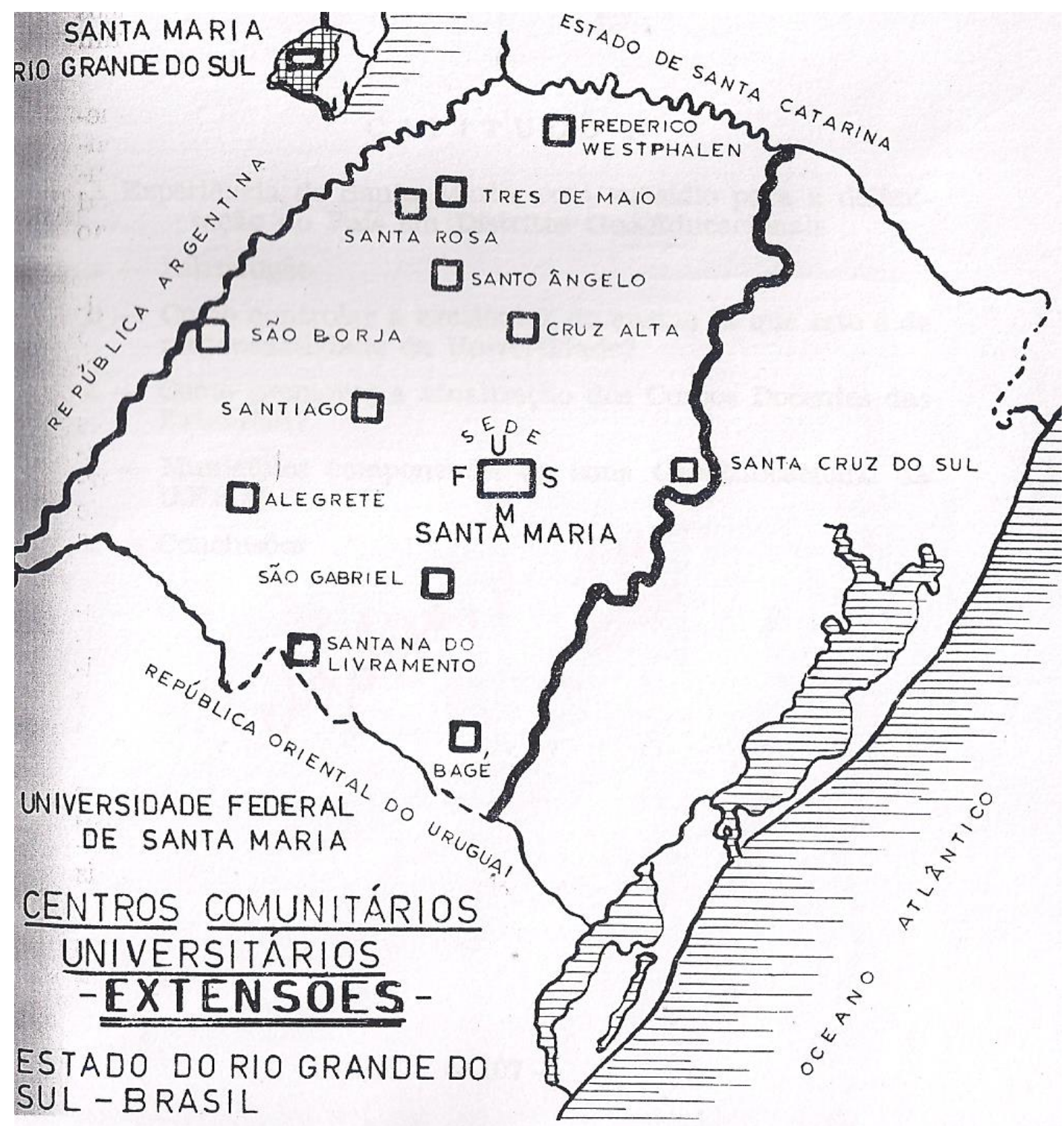

Figura 3. Mapa das cidades do Rio Grande do Sul com campus da UFSM. Fonte: Rocha Filho, 1973, p. 105.

No seu escrito A experiência de Santa Maria, como subsídio para a delimitação do país em Distritos Geo-Educacionais, ${ }^{8}$ elaborado quando essa questão estava em debate no MEC em 1973, Mariano Rocha se pergunta: Como controlar a excelência do ensino nas extensões, já que este é da responsabilidade da Universidade? Informa que foi acertado que à UFSM “caberia a orientação Didático-Pedagógica, vinculando a responsabilidade de seu

\footnotetext{
${ }^{8} \mathrm{O}$ autor, neste texto, defende fortemente seus pontos de vista, que estavam sendo contestados, sobretudo, na delimitação dos Distritos Geo-educacionais. No seu entender, estes deviam se processar "tendo em conta as Universidades oficiais, cabendo às particulares o papel de colaboradoras" (ROCHA FILHO, 1973, p. 115). A área abrangida pela UFSM, defende o Reitor, deveria abarcar 124 municípios, com toda a metade Oeste do RS, o que não se verificou com a criação do DGE 38.
} 
nome no sucesso do empreendimento" (ROCHA FILHO, 1973, p. 114). Para fiscalizar permanentemente as atividades dos cursos nas extensões criou-se a Coordenação Geral das Extensões. As entidades mantenedoras foram encarregadas do funcionamento dos Cursos, sendo que os nomes indicados passavam pelo crivo da UFSM. Da mesma forma, os professores, para lecionarem, eram obrigatoriamente aprovados. "Nenhuma Extensão pode influir no seu Corpo Docente", sentencia o Reitor (ROCHA FILHO, 1973, p. 114). O controle é rigoroso, com comunicação permanente, visitas periódicas e reuniões mensais. A supervisão inclui vestibular e provas. A grade curricular é fornecida pelo Campus central.

Descreve também que, para a Fundação se comprometer em arcar com todas as responsabilidades de ordem material e financeira, visto a UFSM não "dispender um centavo sequer com este tipo de trabalho" - era firmado um convênio, com cláusulas claras das obrigações das partes. As despesas de deslocamento de Coordenadores eram custeadas pelas mantenedoras. Outra preocupação foi com a atualização do corpo docente, o que foi resolvido com a realização de seminários e cursos realizados em Santa Maria e nas próprias sedes das Extensões.

Sob essas condições, em que os espaços de decisões se encontravam longe tanto geograficamente como politicamente, as camisas-de-força de se verem cumpridores de tarefas e vontades de "técnicos" alheios às realidades locais, as extensões partem, em meados dos 1970 a buscar sua independência. São criadas as Instituições de Ensino Superior, isoladas, autônomas, com suas fundações mantenedoras. As lideranças dão-se conta da necessidade de libertarem-se das amarras da Matriz e propor carreira solo, abrindo o leque de oportunidades de cursos exigidos pela nova conjuntura, num primeiro momento voltado em suprir a carência de professores qualificados (titulados) no sistema de ensino da região, daí os cursos de Letras, Ciências e Estudos Sociais. O passo seguinte foi alcançar a liberdade plena ao obter-se o estatuto de Universidade.

Aliás, percebe-se um processo de gradual limitação por parte do Conselho Federal de Educação da criação de cursos fora da sede do Campus. Ficou paradigmático o Parecer $\mathrm{N}^{\mathrm{o}}$ 848/68, do Conselheiro Newton Sucupira, em que defende que "a universidade não pode invocar sua autonomia didática para justificar a criação indiscriminada de cursos regulares em Municípios distantes de sua sede" (PARECER n. ${ }^{\circ}$ 848/68). Parecer que teve, evidentemente, o voto contrário do conselheiro Mariano da Rocha, em cujo parecer exarou que a multiversidade se impunha por conta da expansão do ensino universitário e que lhe parecia "mais fácil deslocar professores por vários campos sucessivamente do que concentrar grandes massas estudantis em determinadas zonas" (PARECER n. ${ }^{\circ}$ 848/68). Outro Parecer de Clóvis Salgado, determinou que cursos fora de sede deveriam ser reconhecidos pelo CFE após dois anos de funcionamento e que "estes cursos poderão continuar sob a direta responsabilidade da universidade, que os estruturará, como convier, ou serão transformados em escolas isoladas, com nova mantenedora" (PARECER n. ${ }^{\circ}$ 611/69). 
Fixar o jovem ao solo e ao pensamento do Governo Militar

Falando da missão da Nova Universidade, Mariano Rocha vislumbrava que devia ir além de transmitir a cada nova geração os conhecimentos acumulados no passado. Devia "desencadear o progresso, desvendando novos horizontes e propiciando aos país os técnicos de que necessita para o seu pleno desenvolvimento" (ROCHA FILHO, 1973, p. 52). Acrescentava que não bastava à universidade somente a formação técnico-profissional. Precisava dar aos jovens "a consciência de seu papel, na formação do Brasil do futuro, além de incutir-lhes a exata noção do cumprimento dos seus deveres para com Deus, para com a Igreja e para com a Pátria, e de suas responsabilidades para com a comunidade em que vivem" (ROCHA FILHO, 1973, p. 52). Como se vê, para o Reitor, a formação devia ser integral, harmônica, atingindo todas as potencialidades da vida humana, incluindo além da orientação científica, o desenvolvimento dos valores espirituais, noções artísticas, economia, tudo "dentro dos ideais do solidarismo cristão"; deve ocupar-se "da formação do espírito cívico e da consciência social de seus alunos, dentro dos valores da civilização cristã" (ROCHA FILHO, 1973, p. 52).

Por fim, arremata que é necessário que a Universidade desenvolva espíritos críticos $e$ sintéticos. E esclarece: "Espírito crítico verdadeiro é aquele que é capaz de construir ao se analisar e propor soluções para um determinado problema, antes de simplesmente desmanchar o pouco que existe, sem propor algo melhor" (ROCHA FILHO, 1973, p. 52).

O autor igualmente critica as reformas em curso em alguns países da América Latina, que, ao seu entender, erraram a receita ao concluírem na necessidade de interferência dos alunos e ex-alunos na direção da Universidade. Da mesma forma, alfineta a reforma de Córdoba (1918), como uma tentativa de implantar "no seio das universidades, de extremismos, promovendo uma luta de classes, onde o professorado representava a burguesia e os alunos constituíam o proletariado (sic)" (ROCHA FILHO, 1973, p. 50). Tal mudança, para o educador, tinha por finalidade abalar a sociedade através do desprestígio da Universidade e de suas autoridades constituídas. Como se vê, participação é termo proibido na cartilha do Reitor. E o principal é autoridade.

\section{CONSIDERAÇÕES FINAIS}

O estudo das obras de Mariano Rocha Filho evidencia, entre outras conclusões, como ele vivia um paradoxo ideológico. Teve uma formação nos princípios patriarcais e católicos que recebem contestações nos anos 1960. Opta pelo caminho da preservação desses valores e propostas, que vão coincidir em muito com os mentores do Golpe de 1964, tornando-se fiel aliado, o que lhe permite implementar seus projetos. Por outro lado, na área da educação, percebeu os novos tempos e busca, no figurino do ensino americano, sobretudo de nível

\begin{tabular}{l|l|l|l|l|l|l|} 
(C) Rev. Inter. Educ. Sup. & Campinas, SP & v.3 & n.1 & p.6-26 & jan./abr. 2017 & ISSN 2446-9424 \\
\hline
\end{tabular}


superior, o modelo para tirá-lo do atraso e fazê-lo um instrumento de desenvolvimento. Excluindo estruturas e modos de gestão que considerava arcaicas, imprime uma organização universitária racional e eficiente, pelo menos em termos de custos e número de formados. Antecede em um decênio muitas das Reformas de 1968. Inova também ao conceber a Universidade como responsável e emulador de políticas públicas voltadas a sanar problemas graves que emperravam o progresso de regiões historicamente deprimidas. Vendo em sua obra, a UFSM, um destino de redimir toda a região de influência, acompanha os desejos de municípios em terem seus próprios colégios de formação superior. Aplica o modelo "Multiversidade", que num primeiro momento resolve o problema, mas vê-se logo-logo deficitário, por seu caráter centralizador e autoritário. As extensões optam por sua autonomia. Como se vê, o reitor, em meio a um mundo dividido, ansioso por "aggiornamento", moveuse entre "Progresso" e "Ordem", ou uma modernidade e conservadorismo. 


\section{REFERÊNCIAS}

ASSOCIAÇÃO NACIONAL DE HISTÓRIA . SEÇÃO RIO GRANDE DO SUL, 12: 2012, Rio Grande. Anais eletrônicos... Disponível em: <http://www.eeh2012.anpuhrs.org.br/resources/anais/18/1346381573_ARQUIVO_2012>. Acesso em: 15 abril 2016.

ARISPE, Fernanda. José Mariano da Rocha Filho: o pai dedicado que fundou a UFSM. Site UFSM. Postado em 06/03/2012. Disponível em: 〈http://site.ufsm.br/noticias/exibir/2101〉. Acesso em: 15 abr. 2016.

DIÁRIO DE SANTA MARIA. Uma vida pela educação. Postado em 13/02/2015. Revista MIX conta a trajetória de José Mariano da Rocha Filho. Disponível em: $<$ http://diariodesantamaria.clicrbs.com.br/rs/cultura-e-lazer/noticia/2015/02/revista-mixconta-a-trajetoria-de-jose-mariano-da-rocha-filho-4700134.html>. Acesso em: 15 abr. 2016.

LIMA, Mateus da F. C.; KONRAD, Diorge A. Entre apoios e resistências: o golpe civilmilitar e o movimento estudantil em Santa Maria. In: ENCONTRO ESTADUAL DE HISTÓRIA, 11.: 2012: Rio Grande. Anais eletrônicos... Rio Grande: [s.n.], 2012.

LUIZ, Pe. Pedro. A Ação Católica nas zonas rurais: I. Vida e Cultura, Ano 5, n.4, abr. 1941.

NEVES, Clarissa E. B. Ensino superior no RS: interiorização e modelos regionais. In: MOROSINI, Marília; LEITE, Denise (Org.). Universidade e integração no Cone Sul. Porto Alegre: Ed. da UFRGS, 1992. p. 95-112.

BRASIL. Ministério da Educação. Conselho Federal de Educação. Parecer Conselho Federal de Educação n. ${ }^{\circ}$ 848/68. Disponível em: 〈http://livros01.livrosgratis.com.br/cd011669.pdf〉. Acesso em: 15 abr. 2016.

BRASIL. Ministério da Educação. Conselho Federal de Educação. Parecer Conselho Federal de Educação n..$^{\circ}$ 611/69. Disponível em <http://www.dominiopublico.gov.br/ download/texto/cd004582.pdf>. Acesso em: 15 abr. 2016.

REVISTA CONEXÃO UFSM. “Cronologia de José Mariano da Rocha Filho”, Santa Maria, n.1, 2010. Disponível em: 〈http://coral.ufsm.br/revista/numero01/cronologia.html>. Acesso em: 15 abr. 2016.

ROCHA FILHO, José Mariano da. A terra, o homem e a educação. Santa Maria: Pallotti, 1993.

ROCHA FILHO, José Mariano da. A nova universidade. Porto Alegre: ASPES/Globo, 1962.

ROCHA FILHO, José Mariano da. A Razão, Santa Maria, 1 maio 1949.

ROCHA FILHO, José Mariano da. Universidade para o desenvolvimento. Áreas (distritos) geo-educacionais. Santa Maria: Imprensa Universitária, 1973. 
ROCHA FILHO, José Mariano da. A Universidade de Santa Maria. In: Revista do Instituto Histórico e Geográfico de Santa Maria, ano 1, n. 1, 1962.

ROSSATO, Ricardo. "As condições da pesquisa na UFSM”, in FRANCO, Maria Estela Dal Pai (Org.). Universidade, pesquisa e inovação: o rio Grande do Sul em perspectiva. Passo Fundo: Ediupf; Porto Alegre: Edipucrs, 1997.

UNIVERSIDADE FEDERAL DE SANTA MARIA (UFSM). Centro de Ciências Sociais e Humanas. Curso de Administração. Projeto Político Pedagógico. Disponível em:

<www.ufsm.br/adm/docs>. Acesso em: 15 abr. 1916. 